\title{
Defining ecosystem processes of the Australian Great Artesian Basin springs from multi-sensor synergies
}

\author{
D.C. White and M.M. Lewis \\ School of Earth \& Environmental Sciences, The University of Adelaide, South Australia \\ Email: davina.white@adelaide.edu.au
}

\begin{abstract}
The Australian Great Artesian Basin (GAB) supports a unique and diverse range of ecologically significant groundwater-fed wetland ecosystems termed GAB springs. The springs are of great national and international importance for their ecological, scientific and economic values, and are culturally significant to indigenous Australians. The ecological sustainability of the springs has become uncertain in recent times due to increased mining operations and associated groundwater extractions from the GAB. The impacts of existing water extractions from the time of European settlement, pastoral activities and more recently mining are largely unknown. This situation is compounded by the likelihood of future increasing demand of water extractions for mining operations.
\end{abstract}

The GAB springs are spatially disparate ecosystems located within the arid interior of South Australia, akin to islands in their ecological setting. The springs exhibit a diverse range of geomorphology, hydrogeology, surface expressions and vegetation community composition over a wide range of spatial scales. A suite of remote sensing technologies were used to capture the range of scales of the spring wetlands and their surface expressions. This multi-sensor approach enabled definition of the spatial and temporal responses of dominant plant species, communities and entire wetlands. To validate the suite of satellite and airborne imagery several comprehensive field campaigns were conducted, capturing the variation in spring vegetation communities and surface expressions. This paper provides a review highlighting the sensor synergies that can be drawn from research conducted from the Australian National Water Commission flagship research program, Allocating Water and Maintaining Springs in the Great Artesian Basin, which has developed new spatial and temporal tools for monitoring indicators of GAB spring response to water allocations and land use (Lewis et al., 2013). The main objectives of this study included: mapping the location and elevation of western GAB springs using high-precision DGPS; development of protocols for ground-based image validation data; develop techniques for detection and monitoring of the surface characteristics of spring-fed wetlands and surrounding environments using fine spatial and spectral resolution imagery; define the short and long-term temporal dynamics of the springs of indicative vegetation types and entire wetlands; use these remote sensing techniques to provide objective and quantitative information about the spring environments and ecological processes.

The sensors and image analyses employed to address these objectives included: MODIS NDVI time series (annual and seasonal traces of entire wetlands and dominant vegetation types); very high resolution multispectral satellite (detailed delineation of wetland extents using NDVI thresholds) and airborne hyperspectral imagery (detailed discrimination of spring plant communities and surrounding substrate using spectral matching algorithms); supported by concurrent colour digital aerial photography and collection of near-concurrent in-situ ecological and spectral data for image calibration and validation purposes. The main focus of this review paper is to draw synergies from the image analyses and research findings that can uniquely be provided using this suite of image data in combination, over differing temporal and spatial scales, to provide new understanding of the drivers and ecological processes underpinning the springs.

The multi-sensor approach revealed for the first time the spatial and temporal responses of these unique ecosystems to changing climatic conditions, land use change and groundwater extractions. Our results reveal that long-term variation is an inherent signature of the wetlands, with distinct phenological responses for differing vegetation species being driven by seasonal temperature and rainfall. In addition the springs were found to change over short time periods (2-3 years) in response to rainfall and land use change, expressed as changing trajectories of outflow channels and inter-connectivity between springs.

This research provides a baseline definition of the long-term natural variation within these groundwater-fed ecosystems as well as their short-term responses to land use changes and water extractions. These outcomes provide an ideal platform for developing models to predict responses of these ecosystems to present local anthropogenic changes in the region and to global climate change.

Keywords: $\quad$ Spatial indicators, Ecological processes, Remote sensing 


\section{INTRODUCTION}

Despite the importance of the GAB as a water resource and the significance of the springs it supports, few of the associated wetlands have been well documented in South Australia. Accurate and repeatable methods are required for baseline inventory and monitoring for these remote, isolated and spatially dispersed groundwater-dependent ecosystems, which contain many rare, relic and endemic flora and fauna. Such spatially accurate information will play a critical role in monitoring future impacts of groundwater extractions for proposed mining in the region and continued use of the water resource by pastoralists. This paper presents a review and synthesis of key findings from the suite of remotely sensed, spatial and ecological data analysed as part of the Australian National Water Commission flagship research program, Allocating Water and Maintaining Springs in the Great Artesian Basin. The project has developed new spatial and temporal tools for monitoring indicators of GAB spring response to water allocations and land use (Lewis et al., 2013). We applied a range of advanced remote sensing and spatial technologies to provide new insights into the spatial distribution and variability, vegetation composition, temporal dynamics and function of groups of springs in the south-western margin of the GAB. This paper presents the key findings of the use and suitability of data of different spatial, spectral and temporal resolutions for detecting, characterising and monitoring $\mathrm{GAB}$ springs. Inferences that can be drawn about the ecosystem processes operating within these groundwater-fed wetlands are highlighted. Analytical approaches were designed and tested with remotely sensed imagery to provide standardised repeatable mapping and monitoring of the springs. These are of particular relevance to natural resource management and other stakeholders using these artesian waters. A key question underpinning this research is whether future demands for extracting GAB groundwater can be balanced with sustainable ecosystem processes maintaining the presence and natural persistence of the springs, which have existed for around 750,000 years (Gotch, 2013; Love et al., 2013).

The main objectives of the Allocating Water and Maintaining Springs in the Great Artesian Basin study were to

- map the location and elevation of western GAB springs using high-precision Differential Global Positioning Systems (DGPS) and compile baseline information on their ecological value and flow status

- develop protocols for collection of ground-based image validation data to enable repeatable and accurate monitoring using image-based techniques

- develop and evaluate new techniques for detection and monitoring of the surface characteristics of western GAB spring-fed wetlands and surrounding environments using fine spatial and spectral resolution imagery

- define the short and long-term temporal dynamics of the GAB springs of indicative vegetation types and entire wetlands using broad scale high temporal resolution satellite imagery

- use these remote sensing techniques to provide objective and quantitative information about GAB spring environments and ecological processes, including spatial and temporal variation in their extent and distribution, phenology and composition in relation to anthropogenic and climatic influences.

The sensors employed to address these objectives included: MODIS (moderate spatial resolution with high temporal frequency - 16 day composites over an 11 year time trace); very high resolution multispectral satellite (fine spatial resolution with targeted temporal short-term frequency) and airborne hyperspectral imagery (fine spectral and spatial resolution with targeted temporal short-term frequency); supported by concurrent colour digital aerial photography ( $30 \mathrm{~cm}$ spatial resolution). The main focus of this review paper is to draw synergies from the image analyses and research findings that can uniquely be provided using this suite of image data in combination, over differing temporal and spatial scales. The results of this study provide a comprehensive understanding of the current status and condition of the western margin GAB springs, while the new tools developed will allow ongoing monitoring of these remote and disparate ecosystems and provide a platform for predictive monitoring based on current trends.

\section{GREAT ARTESIAN BASIN SPRINGS}

The Australian GAB springs, which fringe the western margin of the basin in South Australia (Figure 1), comprise a wide variation in spatial scale, surface forms, floristic composition, geomorphological and hydrogeological settings within an arid landscape. The stability and consistency of groundwater outflow from the $\mathrm{GAB}$ over thousands of years is primarily what has driven the ecological significance of the springs (Gotch, 2013; Love et al., 2013). The isolated nature of the springs has led to the natural preservation of 
many endemic, rare and relict flora and fauna (Fensham et al., 2010; Guzik et al., 2012; Murphy et al., 2012) which are of particular ecological, evolutionary and biogeographical importance (Lewis et al., 2013).
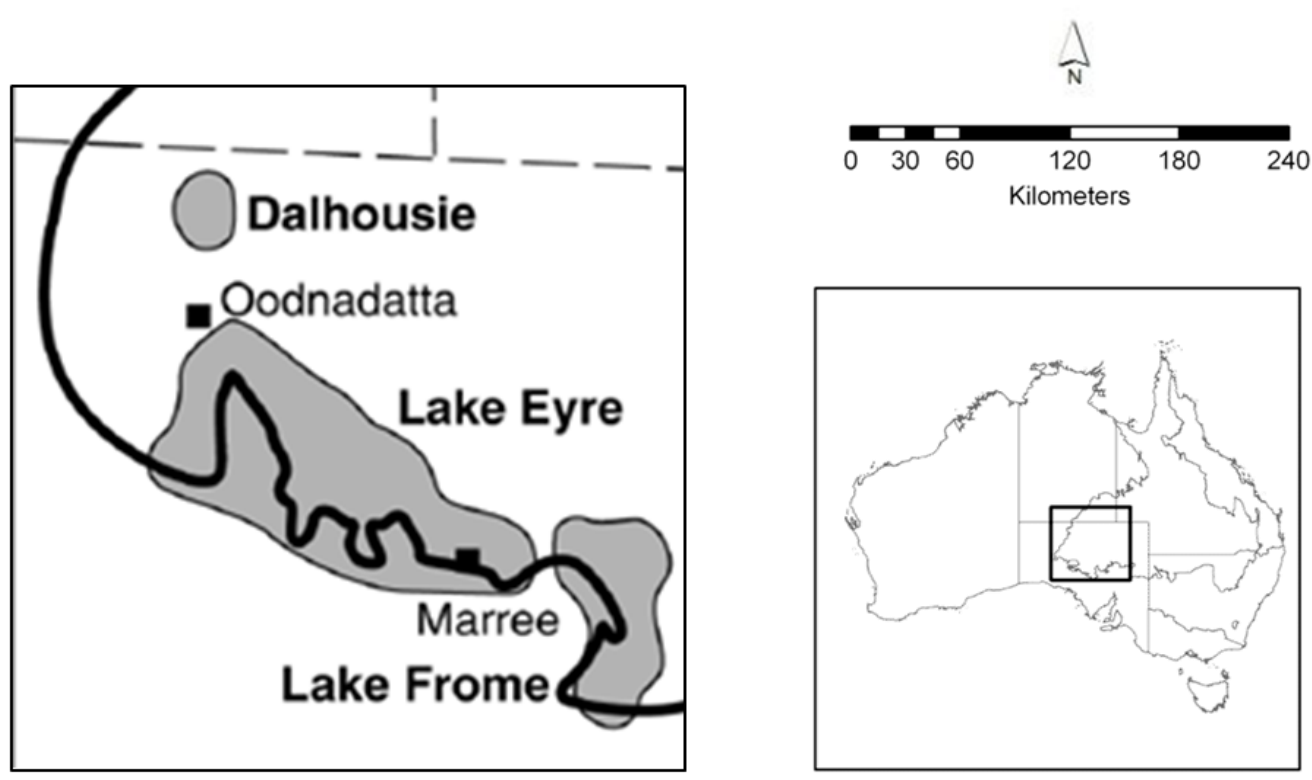

Figure 1. Study area including the Great Artesian Basin and location of western margin spring complexes.

\section{METHODOLOGY}

\subsection{Conceptual approach}

Because of the remote and isolated location of the springs traditional field-based methods of survey and monitoring are difficult and expensive, and limited in their ability to capture the spatial variation and inherent dynamic nature of these unique ecosystems. Remote sensing approaches offered an alternative with potential for objective, repeatable and spatially comprehensive environmental assessment.

Even so, the nature of the GAB wetlands and their geographic context posed considerable challenges for remote sensing and field study: selection, commissioning and collection of appropriate data for the diversity of spatial, temporal and ecological scales were critical. Consequently, the study evaluated and used a wide range of imagery and analytical methods, including MODIS NDVI time series, very high resolution multispectral satellite and airborne hyperspectral imagery, supported by collection of near-concurrent in-situ ecological and spectral data for image calibration and validation purposes. The resultant spatial and image based outputs were synthesised to provide new understanding of the drivers and ecological processes underpinning the springs (Figure 2). 


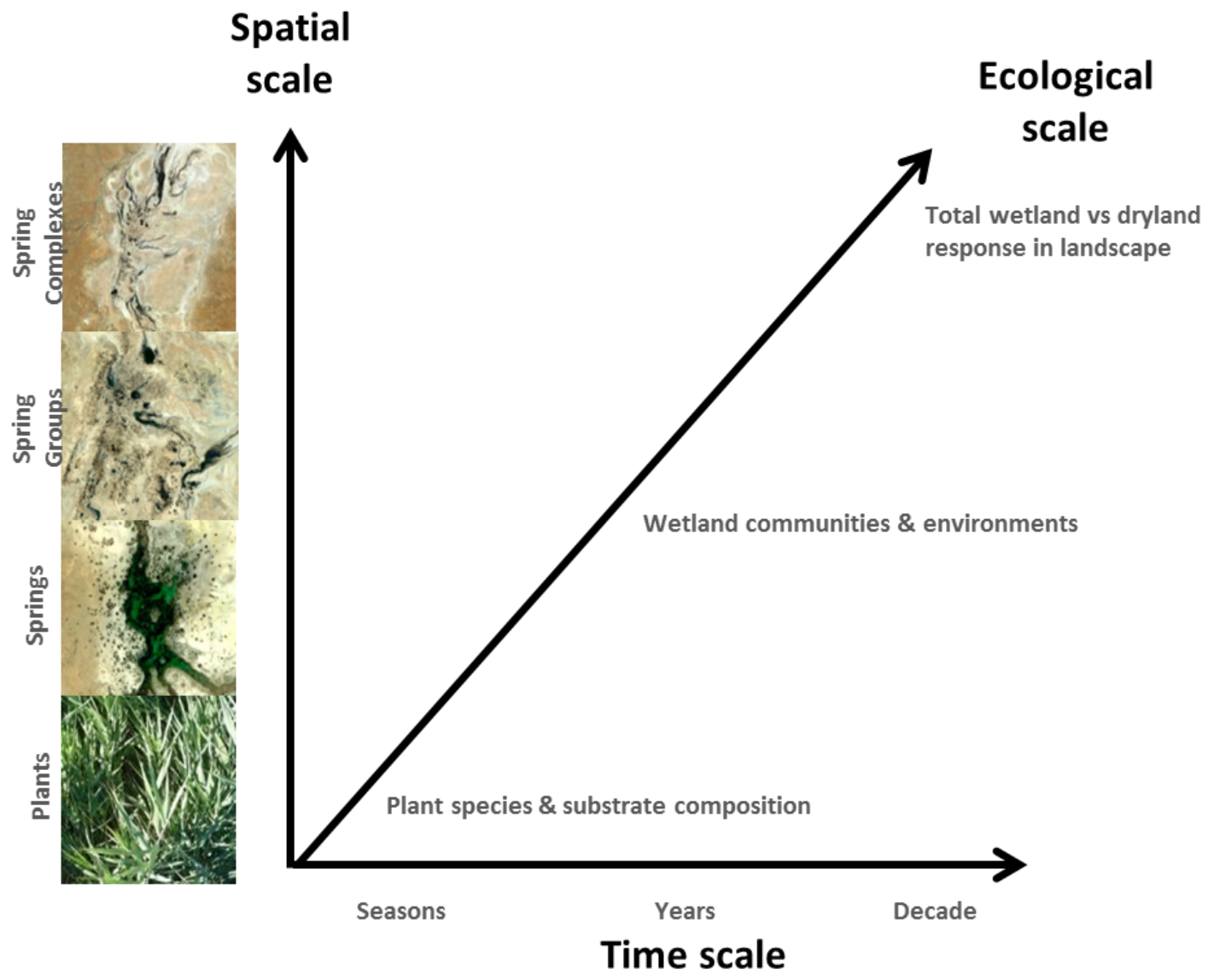

Figure 2. Conceptual approach to determine the ecological scales required for selecting spatial and temporal resolution remotely sensed imagery.

\subsection{Data collection}

Standardized field methods were developed and tested at the selected focal sites to determine the floristic composition, surface expression and vegetation cover of the wide variation in spring forms, surface expressions, ecological, geomorphological and hydrogeological settings along the GAB western margin. Careful consideration was given to the most appropriate methods for defining the ecological characteristics of the spring wetlands including their wide ranging spatial extents, varying vegetation composition and their isolated and dispersed spatial locations within an arid and remote environment. This required a flexible approach which recorded with sufficient spatial detail key ecological attributes of the springs whilst enabling the wide variation in spring surface expressions and landscape settings to be captured in the image data. It also required on-ground data collection to be as coincident as possible with the image capture windows. Data collection involved several field campaigns recording vegetation cover, composition and surrounding substrate in $9 \times 9 \mathrm{~m}$ botanical survey plots, groundwater flow recordings, DGPS locations of spring vents and survey plots coincident with airborne and spaceborne image acquisitions. These ground-based data were used primarily for improved characterization of the current status of the springs and for calibration and validation of image analyses and outputs.

\subsection{Image data and analyses}

Several forms of image analyses were performed which were best suited to the particular types of image data used in the study, most notably

- NDVI time series of entire wetlands over 11 years using $250 \mathrm{~m}$ moderate spatial resolution MODIS 16 day composites;

- NDVI seasonal time traces of dominant spring vegetation types and communities using $250 \mathrm{~m}$ moderate spatial resolution MODIS 16 day composites; 
White and Lewis, Defining ecosystem processes of the GAB springs from multi-sensor synergies

- Detailed delineation of wetland extent for entire wetlands and individual springs for detecting shortterm changes in spring dynamics and to develop a relationship between groundwater flow rates and wetland extent using high spatial resolution $(1.85-2.62 \mathrm{~m}$ ) multispectral (visible to near-infrared wavelength range: QuickBird - four bands; WorldView-2 - eight bands) satellite imagery;

- Detailed discrimination of spring plant community composition and surrounding substrate as well as short-term responses to rainfall and climate of spring groups using airborne hyperspectral imagery (126 wavebands ranging from $450-2,500 \mathrm{~nm} ; 3 \mathrm{~m}$ spatial resolution) and spectral matching algorithms (Mixture Tuned Matched Filtering and Spectral Angle Mapping); and

- Colour digital aerial photography, captured concurrently with the hyperspectral imagery at $30 \mathrm{~cm}$ spatial resolution, for enhanced image interpretation and validation.

The outputs of these image analyses and their interpretation enabled spatial and temporal quantitative ecological information to be interpreted in synthesis drawing findings which in isolation would not have been identified about the dynamic nature of the springs and their environmental drivers.

\section{DEFINING GAB SPRINGS ECOSYSTEM PROCESSES VIA SPATIAL AND TEMPORAL ANALYSIS OF SPRING COMPOSITION AND DYNAMICS}

Interpretation of 11 years of MODIS NDVI hyper-temporal image data revealed considerable intra and interannual variation in greenness and extent within the spring wetlands (Petus et al., 2013). This high-frequency, long-term analysis also identified the characteristic phenological cycles of dominant wetland species, which differentiated them from riverine and dryland vegetation. These seasonal variations in wetland plants were found to be driven by climate parameters, particularly temperature and seasonal rainfall patterns. The NDVI time traces of entire wetland extents and seasonal variations in dominant wetland plants enabled the optimal timing for capture of higher spatial and spectral resolution studies of spring dynamics to be defined, and provided temporal context for image-derived short-term changes. Spatially comprehensive and detailed shortterm dynamics of entire wetlands and individual springs was achieved from NDVI analysis of QuickBird and World View-2 high spatial resolution multispectral satellite imagery, which documented changes in wetland extent, spatial distribution and dynamics of spring tails (White and Lewis, 2013). When linked to spring flow data, wetland areas derived from the high spatial resolution satellite imagery are providing a new tool for

Table 1. Key recommendations of sensors for defining GAB spring ecology

\begin{tabular}{|c|c|c|}
\hline Sensor & Sensor technical specifications & $\begin{array}{l}\text { Capability for defining spring } \\
\text { ecological processes }\end{array}$ \\
\hline $\begin{array}{l}\text { MODIS multispectral } \\
\text { satellite imagery (coarse } \\
\text { spatial resolution, high } \\
\text { temporal frequency) }\end{array}$ & $\begin{array}{ll}- & 36 \text { wavebands } \\
\text { - } & 620-14,385 \mathrm{~nm} \text { wavelength range } \\
\text { - } & 50-300 \mathrm{~m} \text { band width } \\
\text { - } & 250-1,000 \mathrm{~m} \text { spatial resolution } \\
\text { - } & 2,330 \mathrm{~km} \text { (across track) swath width }\end{array}$ & $\begin{array}{ll}- & \text { Long-term trends in wetland } \\
\text { greenness } \\
\text { - } & \text { Inter-annual variability in wetlands } \\
\text { - } & \begin{array}{l}\text { Phenological differentiation of } \\
\text { dominant spring, riverine and } \\
\text { dryland plant communities }\end{array}\end{array}$ \\
\hline $\begin{array}{l}\text { QuickBird and WorldView-2 } \\
\text { multispectral satellite } \\
\text { imagery (fine spatial } \\
\text { resolution; several epochs of } \\
\text { imagery) }\end{array}$ & \begin{tabular}{|l} 
Quickbird: \\
$-\quad 4$ wavebands \\
$-\quad 430-918 \mathrm{~nm}$ wavelength range \\
$-\quad 57-101 \mathrm{~nm}$ band width \\
$-\quad 2.62 \mathrm{~m}$ spatial resolution \\
$-\quad 18 \mathrm{~km}$ swath width \\
WordlView-2: \\
$-\quad 8$ wavebands \\
$-\quad 400-1,040 \mathrm{~nm}$ wavelength range \\
$-\quad 31-94 \mathrm{~nm}$ band width \\
$-\quad 1.85 \mathrm{~m}$ spatial resolution \\
$-\quad 16.4 \mathrm{~km}$ swath width
\end{tabular} & 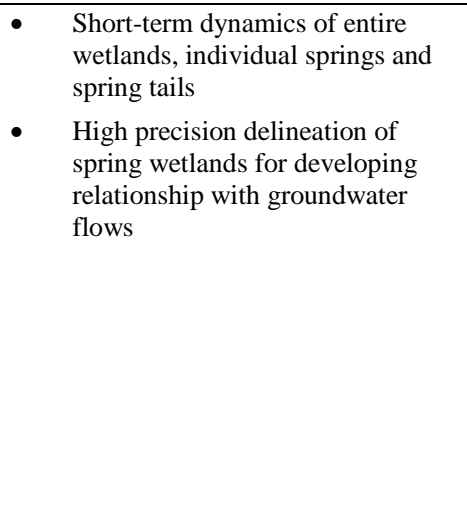 \\
\hline $\begin{array}{l}\text { Hyperspectral airborne } \\
\text { imagery (high spectral and } \\
\text { spatial resolution, two epochs } \\
\text { of imagery) }\end{array}$ & $\begin{array}{ll}- & 124-126 \text { wavebands } \\
\text { - } & 450-2,500 \mathrm{~nm} \text { wavelength range } \\
\text { - } & \sim 15 \mathrm{~nm} \text { band width } \\
\text { - } & \text { 1.5km spatial resolution }\end{array}$ & $\begin{array}{ll}- & \begin{array}{l}\text { Discrimination of key spring } \\
\text { vegetation communities and } \\
\text { dominant plants }\end{array} \\
\text { - } & \begin{array}{l}\text { Delineation of wetted and salinized } \\
\text { zones surrounding springs }\end{array} \\
\text { - } & \begin{array}{l}\text { Short-term changes in spring tail } \\
\text { connectivity and wetland extent }\end{array}\end{array}$ \\
\hline
\end{tabular}


consistently monitoring changes in spring flow rates for a wide range of spring surface expressions and landscape settings (Lewis et al., 2013). The additional four visible and near-infrared wavebands (Table 1) in the World View-2 satellite imagery detected considerable variation within the wetland communities, enabling more detailed characterisation of ephemeral and perennial vegetation as well as vegetation health.

Spectral matching techniques, Mixture Tuned Matched Filtering and Spectral Angle Mapping, were used to analyse the airborne hyperspectral imagery to discriminate spring wetland vegetation communities and surrounding substrate properties. The analyses revealed considerable quantitative information about landscape and wetland vegetation composition and short-term changes in their spatial distribution: dominant vegetation types were mapped for a wide range of spring scales and surface forms, wetlands were differentiated from surrounding arid vegetation, and key species identified. Saline surface deposits and soil moisture associated with near-surface ground water were characterised with hyperspectral indices. Airborne LiDAR, integrated with high-resolution photography and airborne Eagle hyperspectral imagery in decision tree classifiers demonstrated the benefit of combining the two sources of information for detecting particular vegetation types.

The study provided the first baseline characterisation and mapping of focal groups of vulnerable and ecologically important GAB springs in South Australia. The advanced remotely sensed characterisation of the spatial and temporal variation of the springs is assisting ecologists and natural resource land managers to make informed conservation and resource management decisions for the sustainable management of the GAB springs for future generations. The remote sensing methods developed in this study are reliable and repeatable and provide an objective basis for assessing the spatial and temporal dynamics of GAB spring wetland vegetation associated with changes in spring flow rates. The project demonstrated strategic and integrated use of advanced remote sensing image and ground validation data and analyses to compile a comprehensive picture of the spatial, spectral and temporal characteristics of the wetlands.

The suite of image data representing the ecological spatial and temporal characteristics of the springs revealed new insights about the ecological processes of the springs and their main drivers (Table 1).

\subsection{Recommendations for Natural Resource Management}

The study of GAB springs in South Australia via remotely sensed imagery and supporting ground data has revealed new insights about the spatial composition, temporal dynamics and ecological processes operating in the springs. The outputs and tools developed from this research are particularly valuable for the ongoing preservation and management of these unique and diverse ecosystems, which have been found to be particularly sensitive to climatic variability, land use changes and groundwater extractions. .Key findings from this research indicate that temporal trends are dynamic over short and longer term time frames, also revealing seasonal influences in conjunction with influences of water extractions and land use practices. To determine more detailed quantification of the drivers influencing these trends, along with their individual and collective/cumulative contribution continued monitoring of the springs is required. In light of the interplay of these influences on the ecological functioning and sustainability of the springs a number of recommendations from this study are highlighted for natural resource management, ecology and other stakeholders who use these artesian waters:

- Extension of detailed spectral and spatial characterisation of the wetlands and their surrounding environments to all springs along the western margin of the GAB;

- Extension of spatially detailed satellite image monitoring of springs in the western GAB, particularly at sites vulnerable to groundwater extractions and where land use impacts are occurring or proposed and adjacent bore capping is taking place;

- Continued monitoring of temporal variability and trends in spring ecosystem function (wetland extent and greenness, seasonal variations in plant growth) using ongoing analysis of MODIS satellite imagery;

- Repeat studies at specific sites where baseline characterisation has been established and known localised impacts require monitoring for future changes;

- Wider application of image tools and methodologies in the GAB where springs are vulnerable to mining, land use and changing climatic conditions; and

- Whole of region meta-analysis of the above monitoring data to further develop our understanding of the spatial and temporal dynamics of the ecosystem processes at play within the western margin of the GAB. 
The above will provide timely, repeatable and objective information for decisions to be made about any future impacts and influences of groundwater extractions, land use changes, and climate changes. In turn such information will ensure the preservation of these rare, relic and endemic iconic landscape features enabling the sustainable management of these common goods for all.

\section{CONCLUSION}

This research provides a comprehensive quantitative baseline for defining the long-term natural variation of the western margin $\mathrm{GAB}$ groundwater fed-ecosystems as well their short-term spatial responses to land use changes and water extractions. The more detailed spatial and spectral studies quantifying the surface characteristics of the springs have provided new quantitative information on their status, surface composition and spatial distribution, invaluable for identifying future ecosystem changes. These outcomes provide an excellent basis for developing models to predict responses of these ecosystems to the current anthropogenic changes within the arid region and to potential climate changes.

\section{ACKNOWLEDGMENTS}

The study presented in this paper was conducted as part of a larger multidisciplinary program, "Allocating Water and Maintaining Springs in the Great Artesian Basin”, funded by and involving collaboration between a number of organizations in Australia (Australian National Water Commission, South Australian Government, South Australian Arid Lands Natural Resource Management Board, the Witjira Board of Management, Finders University, the University of Adelaide, and Australian Commonwealth Scientific and Research Organization). The authors acknowledge these organizations for their sponsorship and in-kind support to this project. We also thank the traditional owners and native title holders for allowing us access to their land; Mr Travis Gotch, ecology chief investigator for his expert knowledge of the western margin GAB springs and providing the DGPS data; and everyone who has assisted with field data collection, which was conducted under the Department of Environment and Natural Resources Scientific Research Permit M25809. The authors would like to thank the anonymous reviewers who provided thoughtful comments on the manuscript that helped improve the final paper.

\section{REFERENCES}

Fensham, R.J., Ponder, W.F., Fairfax, R.J., 2010. Recovery plan for the community of native species dependent on natural discharge of groundwater from the Great Artesian Basin, Department of Environment, Water, Heritage and Arts, Queensland Department of Environment and Resource Management, Brisbane.

Gotch, T.B., (ed.) 2013. Allocating water and maintaining springs in the Great Artesian Basin, Volume V: Groundwater-dependent ecosystems of the western Great Artesian Basin, National Water Commission, Canberra.

Guzik, M.T., Adams, M.A., Murphy, N.P., Cooper, S.J.B., Austin, A.D., 2012. Desert springs: Deep endemic crustacean (Phreatomerus latioes). PLoS ONE, 7(7): e37642.

Lewis, M.M., White, D.C., Gotch, T.B., (eds.) 2013. Allocating water and maintaining springs in the Great Artesian Basin, Volume IV: Spatial survey and remote sensing of artesian springs of the western Great Artesian Basin, National Water Commission, Canberra.

Love, A.J., Wohling, D., Fulton, S.A., Rousseau-Gueutin, P., De Ritter, S., (eds) 2013. Allocating water and maintaining springs in the Great Artesian Basin, Volume II: Groundwater recharge, hydrodynamics and hydrochemistry of the western Great Artesian Basin: Introduction, National Water Commission, Canberra.

Murphy, N.P., Breed, M.F., Guzik, M.T., Cooper, S.J.B., Austin, A.D., 2012. Trapped ion desert springs: Phylogeography of australian desert spring snails. Journal of Biogeography, 39: 1573-1582.

Petus, C., Lewis, M., White, D., 2013. Monitoring temporal dynamics of Great Artesian Basin wetland vegetation, Australia, using MODIS NDVI. Ecological Indicators, 34: 41-52.

White, D.C., Lewis, M.M., 2011. A new approach to monitoring spatial distribution and dynamics of wetlands and associated flows of Australian Great Artesian Basin springs using QuickBird satellite imagery. Journal of Hydrology, 408: 140-152. 